\title{
BMJ Global Health Food insecurity as a risk factor for preterm birth: a prospective facility- based cohort study in rural Haiti
}

Aaron Richterman, ${ }^{1,2}$ Maxi Raymonville, ${ }^{3}$ Azfar Hossain, ${ }^{4}$ Christophe Millien, ${ }^{3}$ Jean Paul Joseph, ${ }^{3}$ Gregory Jerome, ${ }^{3}$ Molly F Franke, ${ }^{5}$ Louise C Ivers (i) ${ }^{2,5}$

To cite: Richterman $A$,

Raymonville M, Hossain A, et al. Food insecurity as a risk factor for preterm birth: a prospective facility-based cohort study in rural Haiti. BMJ Global Health 2020;5:e002341. doi:10.1136/ bmjgh-2020-002341

Handling editor Seye Abimbola

Received 24 January 2020

Revised 8 May 2020

Accepted 11 May 2020
Check for updates

(C) Author(s) (or their employer(s)) 2020. Re-use permitted under CC BY-NC. No commercial re-use. See rights and permissions. Published by BMJ.

${ }^{1}$ Division of Infectious Diseases, Brigham and Women's Hospital, Boston, Massachusetts, USA ${ }^{2}$ Center for Global Health, Massachusetts General Hospital Boston, Massachusetts, USA ${ }^{3}$ Partners in Health/Zanmi Lasante, Mirebalais, Haiti ${ }^{4}$ Harvard Medical School, Boston, Massachusetts, USA ${ }^{5}$ Department of Global Health and Social Medicine, Harvard Medical School, Boston, Massachusetts, USA

Correspondence to Dr Aaron Richterman; aarichter@gmail.com

\section{ABSTRACT}

Introduction Haiti has an estimated neonatal mortality rate of 32/1000 live births, the highest in the Western Hemisphere. Preterm birth and being born small for gestational age (SGA) are major causes of adverse neonatal outcomes worldwide. To reduce preterm birth and infants born SGA, it is important to understand which women are most at risk and how risk varies within countries. There are few studies estimating the prevalence and risk factors for these conditions in Haiti, particularly in rural regions.

Methods We conducted a prospective cohort study of pregnant women at a rural tertiary care centre in Haiti from May to December 2017. We collected data during interviews and from the medical record. We built multivariable models to identify risk factors for preterm birth and being born SGA among women who had a facility-based delivery.

Results 1089 pregnant women delivered at the hospital and were included in this analysis. Median gestational age at delivery was 38 weeks (IQR 36-40). In multivariable analyses, risk factors for preterm birth included maternal age $<20$ years (adjusted OR (AOR) $1.76,95 \% \mathrm{Cl} 1.14$ to 2.72 ) and $>34$ years (AOR $1.46,95 \% \mathrm{Cl} 1.01$ to 2.11 ) and severe hunger in the household (AOR 1.57, 95\% $\mathrm{Cl} 1.09$ to 2.26). Risk factors for SGA were age $>34$ years (AOR 1.76, $95 \% \mathrm{Cl} 1.18$ to 2.59 ), twin pregnancy (AOR $3.28,95 \% \mathrm{Cl}$ 1.20 to 8.95 ) and first pregnancy (AOR $1.57,95 \% \mathrm{Cl} 1.12$ to 2.23). Number of prior abortions was associated with reduced risk for SGA (AOR $0.41,95 \% \mathrm{Cl} 0.17$ to 0.97 ). Conclusions Food insecurity as a risk factor for preterm birth stands out as an important addition to the understanding of the risk of neonatal morbidity and mortality. This association highlights a potentially important intervention target to improve birth outcomes and suggests that food support has an important role to play for pregnant women who are food insecure in low-income settings.

\section{INTRODUCTION}

Preterm birth (delivery before 37 weeks gestational age) and fetal growth restriction (manifesting as infants born small for gestational age (SGA), defined as below the 10th percentile of weight for their gestational age) are major causes of neonatal morbidity and

\section{Key questions}

What is already known?

- Preterm birth and infants born small for gestational age (SGA) are major causes of adverse neonatal outcomes worldwide.

- A variety of risk factors for preterm birth and being born SGA have been identified, including nutritional medical, psychosocial and genetic factors, although relatively less is known about risk factors in lowincome countries and rural regions, particularly in Haiti.

What are the new findings?

- We conducted a prospective facility-based cohort study of 1089 pregnant women seeking antenatal care in rural Haiti and delivering at a tertiary care centre to identify risk factors for preterm birth and being born SGA.

- Age less than 20 or greater than 34 years and severe household food insecurity were independently associated with greater odds of preterm birth among women delivering in a rural tertiary referral hospital in Haiti.

- Age greater than 34 years, twin pregnancy and first pregnancy were independently associated with a greater odds of SGA, and number of prior abortions was independently associated with a lower odds of SGA.

\section{What do the new findings imply?}

- Food insecurity as a risk factor for preterm birth stands out as an important addition to the understanding of the risk of neonatal morbidity and mortality.

- The association between food insecurity and preterm birth highlights a potentially important intervention target to improve birth outcomes and suggests that food support has an important role to play for pregnant women who are food insecure in low-income settings.

mortality worldwide, and are accompanied by both short-term and long-term risks. ${ }^{12} \mathrm{~A}$ recent multicountry analysis estimated that the global preterm birth rate for 2014 was $10.6 \%$, with complications of preterm birth 
found to be the leading cause of death in children less than 5 years of age. ${ }^{3}$ A variety of risk factors for preterm birth and SGA have been identified, including nutritional (eg, low pre-pregnancy body mass index, obesity, micronutrient deficiencies), medical (eg, maternal age, diabetes, hypertension, infections, multiple gestations), psychosocial (eg, depression, poverty, substance use) and genetic factors. ${ }^{45}$ Strategies to identify pregnancies at high risk for these outcomes and to intervene on potentially modifiable risk factors are important components of reducing neonatal mortality to less than 12 deaths per 1000 live births in all countries, a key element of Sustainable Development Goal (SDG) 3-to ensure healthy lives and promote well-being for all people at all ages—set by the United Nations in $2015 .{ }^{6}$

Haiti has an estimated neonatal mortality rate of 32 deaths per 1000 live births, the highest in the Latin America and Caribbean region. ${ }^{7}$ The prevalence of newborns with low-birth weight (LBW, birth weight below $2500 \mathrm{mg}$ ) in Haiti is estimated to be $16.6 \%$, although this figure is based primarily on household recall rather than birth record. ${ }^{7}$ There are no available national data regarding preterm birth in Haiti, with reported estimates limited to modelling studies based on other indicators. ${ }^{38}$ Two retrospective studies have evaluated the prevalence and risk factors for LBW and preterm birth in urban Haiti, although these have been limited by small size and lack of multivariable analyses, ${ }^{9} 10$ with one finding that dietary factors and hypertension were associated with preterm birth. ${ }^{9}$ In this study, we sought to better estimate risk factors of preterm birth and SGA in a rural region of Haiti.

\section{METHODS}

\section{Setting and population}

This study is a secondary analysis of a facility-based prospective observational cohort study of pregnant women seeking routine antenatal care at Hôpital Universitaire de Mirebalais (HUM). It was originally conducted to assess for the prevalence of Zika, chikungunya and dengue in pregnant women. HUM is a rural tertiary care centre in the town of Mirebalais in the Centre Department of Haiti. HUM is managed by Partners In Health/Zanmi Lasante in collaboration with the Haitian Ministry of Health. The primary catchment area of HUM contains approximately 180000 people and includes the communes of Mirebalais, Seau d'Eau and Savanette. HUM offers advanced obstetrical care with eight full-time obstetricians-gynaecologists, ultrasounds, six operating rooms and a residency training programme. HUM also provides specialist paediatric services, with eight full-time paediatricians, a neonatal intensive care unit and a residency training programme. There are approximately 600 prenatal clinic visits and 500 deliveries per month at HUM, $25 \%$ of which are caesarean sections.

Women were eligible for the study if they were aged 16 years or older, pregnant with laboratory confirmation, seeking antenatal care at HUM and residing within the catchment area of HUM. All women who met eligibility criteria were recruited for participation. This analysis was restricted to the participants who delivered at HUM. Study participants received a transportation stipend of 150 Haitian Gourdes (approximately \$1.90) at enrolment and again if they returned to HUM for delivery. As part of routine antenatal services at HUM, women were encouraged to have four antenatal visits prior to delivery and to return for a facility delivery.

\section{Data}

Participants were enrolled from May to December 2017. We collected study data through participant interviews and from the medical record.

At the time of enrolment, we conducted a structured survey assessment, collecting information about the participant's age, residential locality, history of alcohol use and obstetrical history (number of prior pregnancies, live births, stillbirths, miscarriages and abortions). We calculated the distance from the centre of the participant's locality to HUM in kilometres and included this variable as a continuous variable in our analysis. We used a previously validated poverty scorecard based on 11 indicators and specific to Haiti to estimate the probability (from 0 to 1 ) that a participant's household had consumption below the national poverty line of 83.39 Haitian Gourdes per day (approximately $\$ 1$ ). ${ }^{11}$ These indicators include the household's administrative department, number of household members, number of household members aged 10 years or older who work, whether the female head of household works, whether the male and female heads of household can read and write, roof material, source of drinking water, source of energy for cooking, whether the household has a stove and whether the household has a radio.

We defined an improved roof as not primarily made of thatch, straw or tarp. We defined an improved water source as piped household water, protected wells or springs, or collected rainwater. Finally, we defined an improved energy source for cooking as one other than wood or straw, such as charcoal, propane, electricity, kerosene or solar.

We assessed for food insecurity, defined as a persistent lack of access to food in adequate quantity or quality, in the survey using two measures: the Household Hunger Scale (HHS), a three-item experiential measure of food access that has been shown to be culturally invariant and classifies households as having no hunger, moderate hunger or severe hunger ${ }^{12}$; and the Food Consumption Score (FCS), a measure of dietary diversity and food access uses recalled consumption frequencies of eight food groups to generate a composite score and classifies households as having acceptable, borderline or poor food security. ${ }^{13}$

Clinical characteristics were abstracted from the medical record at the time of delivery. Gestational age was calculated as the number of days since the start of 
Table 1 Characteristics of pregnant women who presented to Hôpital Universitaire de Mirebalais (HUM) for antenatal care and returned for facility delivery $\left(n=1089^{*}\right)$

\begin{tabular}{|c|c|}
\hline Sociodemographics & $\begin{array}{l}\text { N (\%) or median } \\
\text { (IQR) }\end{array}$ \\
\hline Age, median (IQR) & $27(23-32)$ \\
\hline Gestational age, median (IQR) (N=880) & $24(17-30)$ \\
\hline Mirebalais resident, N (\%) & $773(71)$ \\
\hline Centre department resident, N (\%) & $1028(94)$ \\
\hline $\begin{array}{l}\text { Distance from locality to hospital (km), median } \\
\text { (IQR) }\end{array}$ & $9.0(7.2-10.6)$ \\
\hline No. of household members, median (IQR) $(n=724)$ & $4(3-6)$ \\
\hline Improved roof†, N (\%) & $1038(95)$ \\
\hline Improved water sourceł, N (\%) & $835(77)$ \\
\hline Improved energy source for cooking§, N (\%) & $815(75)$ \\
\hline Pesticide use in past year, $\mathrm{N}(\%)$ & $131(12)$ \\
\hline Ever consumed alcohol, N (\%) & $54(5)$ \\
\hline \multicolumn{2}{|l|}{ Poverty scorecard, median (IQR) (N=724) } \\
\hline Raw score & $57(46-64)$ \\
\hline $\begin{array}{l}\text { Probability of poverty } \\
\text { (100\% National Poverty Line) }\end{array}$ & $0.27(0.16-0.45)$ \\
\hline \multicolumn{2}{|l|}{ Food Consumption Score, N (\%) } \\
\hline Acceptable & $939(86)$ \\
\hline Borderline & $111(10)$ \\
\hline Poor & $39(4)$ \\
\hline \multicolumn{2}{|l|}{ Household Hunger Scale, N (\%) } \\
\hline No hunger in household & $382(35)$ \\
\hline Moderate hunger in household & $326(30)$ \\
\hline Severe hunger in household & $381(35)$ \\
\hline \multicolumn{2}{|l|}{ No. of living children, N (\%) } \\
\hline 0 & $466(43)$ \\
\hline $1-3$ & $522(48)$ \\
\hline$\geq 4$ & $101(9)$ \\
\hline Obstetrical history & $\begin{array}{l}\text { N (\%) or median } \\
\text { (IQR) }\end{array}$ \\
\hline No. of prior pregnancies, median (IQR) & $2(0-2)$ \\
\hline First pregnancy, N (\%) & $402(37)$ \\
\hline \multicolumn{2}{|l|}{ Prior live births, N (\%) } \\
\hline 0 & $455(42)$ \\
\hline $1-3$ & $523(48)$ \\
\hline$\geq 4$ & $111(10)$ \\
\hline Prior stillbirths ( $\geq 1), \mathrm{N}(\%)$ & $92(8)$ \\
\hline Prior miscarriages $(\geq 1), \mathrm{N}(\%)$ & $86(8)$ \\
\hline Prior abortions ( $\geq 1), \mathrm{N}(\%)$ & $51(5)$ \\
\hline
\end{tabular}

*Unless otherwise noted.

†Not primarily made of thatch, straw or tarp.

¥Piped household water, protected wells or springs, collected rainwater §A source other than wood or straw.

IRange from 0 to 1.

HUM, Hôpital Universitaire de Mirebalais; km, kilometre.

the last menstrual period (LMP). Preterm birth was defined as delivery before 37 weeks gestational age, and SGA was defined as weight below the 10th percentile for gestational age. Maternal and fetal birth outcomes were collected for all participants. Apgar scores were calculated at 1 and 5 min after birth.

\section{Statistical analysis}

We reported baseline characteristics and outcomes using $\mathrm{N}(\%)$ for proportional data and median (IQR) for continuous data. We used multivariable analyses to identify risk factors for preterm birth and SGA. For preterm birth, the unit of analysis was the mother, and we built multivariable logistic regression models. For SGA, the unit of analysis was the newborn, and we built a multivariable generalised estimating equations (GEE) model with an exchangeable correlation structure to account for clustering within twin pregnancies. For each outcome, we considered risk factors that were either previously identified in other settings or biologically plausible. ${ }^{45} \mathrm{We}$ first calculated unadjusted OR with $95 \%$ CI between the baseline characteristics and the outcome. We then incorporated probability of poverty (per 0.1 increase) and all variables correlating in bivariate models with a particular outcome with $\mathrm{p}<0.2$ into the final multivariable model for that outcome. We chose a $\mathrm{p}<0.2$ threshold because it was likely to result in the most plausible risk factors while also adjusting for likely confounders of those risk factors.

\section{Missing data}

We unintentionally omitted the question regarding number of household members from the survey form used during the first several months of the study. As a result, this covariate (and the resulting poverty score) is missing for $34 \%$ of the participants. There was no missingness for the other baseline characteristics. To account for the missing poverty score, we performed multiple imputation $(n=25)$ by covariate and outcome data using the fully conditional specification method and generated pooled OR with $95 \%$ CI.

We performed statistical analysis using SAS V.9.4 (SAS Institute).

\section{Ethics}

All participants provided written informed consent.

\section{Patient and public involvement}

Patients and the public were not involved in the design, conduct and reporting of this research.

\section{RESULTS}

We enrolled 1713 pregnant women presenting for antenatal care between May and December 2017. Of these, $1089(64 \%)$ gave birth at HUM and were included in this analysis (table 1 ). The median age was 27 years (IQR 23-32), with a median gestational age at enrolment of 24 weeks (IQR 17-30). The vast majority of the participants resided in the Centre Department in towns less than $10 \mathrm{~km}$ from HUM and in households with a median of 4 members (IQR 3-6). While there were high rates of poverty and food insecurity among participants, the majority reported having an improved roof, access to an 
Table 2 Birth outcomes for pregnant women who presented to Hôpital Universitaire de Mirebalais (HUM) for antenatal care and returned for facility delivery $(\mathrm{N}=1089$ mothers*; $N=1104$ infants ${ }^{\star}$ )

$218(20)$

Caesarean section, N (\%)

Gestational age at delivery, median (IQR) $38(36-40)$
(N=972)

Gestational age at delivery, N (\%)

$(\mathrm{N}=972)$

\begin{tabular}{|c|c|}
\hline$\geq 37$ weeks (term) & $621(64)$ \\
\hline 32-37 weeks (late preterm) & $314(32)$ \\
\hline 28-32 weeks (very preterm) & $32(3)$ \\
\hline$<28$ weeks (extreme preterm) & $5(1)$ \\
\hline \multicolumn{2}{|l|}{ Infant outcomes $(\mathrm{N}=1104)$} \\
\hline \multicolumn{2}{|l|}{ Birth outcomes, N (\%) } \\
\hline Live birth & 1089 (99) \\
\hline Neonatal death & $6(1)$ \\
\hline Stillbirth & $9(1)$ \\
\hline Birth weight $(\mathrm{mg})$, median (IQR) $(\mathrm{N}=1042)$ & $3000(2710-3300$ \\
\hline Low birth weight†, $N(\%)(\mathrm{N}=1042)$ & $142(14)$ \\
\hline $\begin{array}{l}\text { Small for gestational age } \neq, N(\%) \\
(\mathrm{N}=977)\end{array}$ & $258(26)$ \\
\hline \multicolumn{2}{|l|}{ Apgar $-1 \min , \mathrm{N}(\%)(\mathrm{N}=1008)$} \\
\hline Normal $(\geq 7)$ & $944(94)$ \\
\hline Low (4-7) & $49(5)$ \\
\hline Severely low $(<4)$ & $15(1)$ \\
\hline \multicolumn{2}{|l|}{ Apgar $-5 \mathrm{~min}, \mathrm{~N}(\%)(\mathrm{N}=1008)$} \\
\hline Normal $(\geq 7)$ & $981(97)$ \\
\hline Low (4-7) & $20(2)$ \\
\hline Severely low $(<4)$ & $7(1)$ \\
\hline
\end{tabular}

*Unless otherwise noted.

$\dagger<2500 \mathrm{mg}$.

$\ddagger<10 \%$ weight by gestational age.

HUM, Hôpital Universitaire de Mirebalais.

improved water source and an improved energy source for cooking. Participants reported a median of 2 (IQR 0-2) prior pregnancies, and 402 (37\%) participants were primigravid.

Characteristics of the participants who enrolled in the study and attended HUM for delivery compared with those who did not attend for delivery will be described in detail in another report. ${ }^{14}$

Of 1089 participants, $218(20 \%)$ had a caesarean section. There was a total of 1104 infants, with 15 pairs of twins (table 2). There were 1089 (99\%) live births, $9(1 \%)$ stillbirths and $6(1 \%)$ live births with neonatal death recorded (defined as death within 28 days of delivery). The median gestational age at delivery was 38 weeks (IQR 36-40), with most deliveries at term $(n=621$; $64 \%)$ and $314(32 \%)$ late preterm, $32(3 \%)$ very preterm and $5(1 \%)$ extremely preterm. The median infant birth weight was $3000 \mathrm{mg}$ (IQR 2710-3300) and 258 (26\%) were SGA. Apgar scores were normal for the vast majority of infants at 1 and 5 min after delivery.

In univariable analyses for risk factors for preterm birth, age, pesticide use and HHS met the criteria for inclusion in the multivariable model (table 3 ). In the multivariable model, compared with age 20-34 years, age less than 20 (AOR 1.76, 95\% CI 1.14 to 2.72, $\mathrm{p}=0.01$ ) and greater than 34 (AOR $1.46,95 \%$ CI 1.01 to $2.11, \mathrm{p}=0.044$ ), as well as severe hunger in the household relative to no hunger in the household (AOR 1.57, 95\% CI 1.09 to 2.26, $\mathrm{p}=0.02$ ) were independently associated with a higher odds of preterm birth.

In univariable analyses for risk factors for infants born with SGA, age, twin pregnancy, first pregnancy, number of prior stillbirths and number of prior abortions met the criteria for inclusion in the multivariable model (table 4). In the multivariable model, age greater than 34 years compared with age 20-34 years (AOR 1.76, 95\% CI 1.18 to $2.59, \mathrm{p}=0.01$ ), twin pregnancy (AOR $3.28,95 \% \mathrm{CI} 1.20$ to $8.95, \mathrm{p}=0.019$ ), first pregnancy (AOR $1.57,95 \% \mathrm{CI} 1.12$ to $2.23, \mathrm{p}=0.0085$ ) and number of prior abortions (AOR $0.41,95 \%$ CI 0.17 to $0.97, \mathrm{p}=0.044$ ) were independently associated with SGA among infants.

\section{DISCUSSION}

In this prospective facility-based cohort study of 1089 pregnant women receiving antenatal care and delivering at a tertiary care hospital in rural Haiti, $36 \%$ of women had preterm birth, compared with 14\%-25\% reported in retrospective analyses in urban Haiti, ${ }^{8} 10$ and $26 \%$ of live births resulted in a neonate that was SGA. Although there are no national estimates in Haiti for the prevalence of SGA, a large pooled analysis of nine low-income and middle-income countries found that SGA was observed in $19.3 \%$ of live births. ${ }^{15}$ We found that age less than 20 or greater than 34 years and severe household food insecurity were independently associated with greater risk of preterm birth; that age greater than 34 years, twin pregnancy and first pregnancy were independently associated with greater risk of an infant born SGA; and that number of prior abortions was independently associated with a reduced risk of an infant born SGA.

Among these factors, food insecurity, defined as a persistent lack of access to food in adequate quantity or quality, ${ }^{16}$ stands out as an important addition to the understanding of the risk of preterm birth. While food insecurity has been closely linked to a number of adverse health outcomes independent of wealth in a variety of settings and through multiple pathways beyond simply nutritional deficiency, ${ }^{16}$ few studies have evaluated the relationship between food insecurity and preterm birth. One recent study of 674 healthy pregnant women in urban Iran found a twofold increase in the odds of preterm birth among mothers living in food insecure households. ${ }^{18}$ Similarly, a cohort study in urban South 
Table 3 Risk factors at antenatal evaluation for preterm birth among pregnant women who presented to Hôpital Universitaire de Mirebalais (HUM) for antenatal care and returned for facility delivery $(n=972)$

\begin{tabular}{|c|c|c|c|c|c|c|}
\hline \multirow[b]{2}{*}{ Variable } & \multicolumn{3}{|c|}{ Unadjusted } & \multicolumn{3}{|c|}{ Adjusted } \\
\hline & OR & $95 \% \mathrm{Cl}$ & $P$ value & AOR & $95 \% \mathrm{Cl}$ & $P$ value \\
\hline \multicolumn{7}{|l|}{ Age (years) } \\
\hline $20-34$ & Ref & & & Ref & & \\
\hline$>34$ & 1.45 & 1.01 to 2.09 & 0.046 & 1.46 & 1.01 to 2.11 & 0.044 \\
\hline Probability of poverty* & 1.03 & 0.98 to 1.09 & 0.24 & 1.00 & 0.95 to 1.06 & 0.88 \\
\hline Pesticide use in the past year & 1.48 & 0.98 to 2.22 & 0.06 & 1.39 & 0.92 to 2.11 & 0.12 \\
\hline Alcohol use & 1.07 & 0.57 to 2.02 & 0.83 & & & \\
\hline Twin pregnancy & 1.80 & 0.63 to 5.11 & 0.27 & & & \\
\hline First pregnancy & 1.05 & 0.82 to 1.34 & 0.72 & & & \\
\hline No. of prior miscarriages & 0.85 & 0.55 to 1.32 & 0.47 & & & \\
\hline No. of prior abortions & 0.81 & 0.41 to 1.61 & 0.54 & & & \\
\hline \multicolumn{7}{|l|}{ Food Consumption Score } \\
\hline Acceptable & Ref & & & & & \\
\hline Borderline & 1.15 & 0.73 to 1.81 & 0.54 & & & \\
\hline Poor & 1.17 & 0.53 to 2.59 & 0.70 & & & \\
\hline \multicolumn{7}{|l|}{ Household Hunger Scale } \\
\hline No hunger & Ref & & & Ref & & \\
\hline Moderate & 1.33 & 0.92 to 1.90 & 0.13 & 1.27 & 0.88 to 1.83 & 0.21 \\
\hline
\end{tabular}

*Per 0.1 increase in probability of household consumption less than one dollar per day.

HUM, Hôpital Universitaire de Mirebalais; km, kilometre.

Africa found an independent association between food insecurity and gestational age. ${ }^{19}$ Another study in the USA found an association between food insecurity and preterm birth among parous women. ${ }^{20}$

There are a number of plausible pathways by which food insecurity may increase risk of preterm birth. Food insecurity is often characterised by extended periods of time without eating, and one study in the USA found an increased risk of preterm birth for women who experienced periods without food longer than 13 hours. ${ }^{21}$ Food insecurity is associated with worse mental health and an increased stress response during pregnancy, ${ }^{22} 23$ which in turn are associated with higher risk of preterm birth. ${ }^{24-26}$ Food insecurity is likewise associated with chronic inflammation, ${ }^{27} 28$ which is also thought to play a role in preterm birth. ${ }^{29}$ In some cases, food insecurity may lead to poor maternal nutrition, a well-described risk factor for preterm birth. ${ }^{4}$ Consequences of food insecurity may be exacerbated during pregnancy because of higher nutrient demands, a greater effort required for food preparation and the possibility that pregnant women are obligated to leave the workforce, especially late in pregnancy. ${ }^{22}$
The role of food insecurity in preterm birth is especially important in Haiti, one of the most food insecure countries in the world, where more than half of the total population is chronically food insecure. ${ }^{30} 31$ While the impact of interventions targeting food insecurity on preterm birth in low-income countries has not been extensively studied, food assistance programmes in high-income countries have been associated with a reduction in preterm birth and infant mortality, ${ }^{32}$ and in this context, our findings suggest that food support has an important role to play for pregnant women who are food insecure in low-income settings. Interventions targeting food insecurity should be evaluated and implemented with a goal of improving birth outcomes, while existing food assistance programming targeting pregnant women (like that by the World Food Programme in Haiti) should be emphasised and strengthened.

The independent association we found between history of abortion and reduced risk of SGA has been previously reported once in a high-income setting and may relate to abortion being a proxy measure for socioeconomic status. ${ }^{33}$ In Haiti, women with higher socioeconomic status are much more likely to report having 
Table 4 Risk factors at antenatal evaluation for an infant being born small for gestational age (SGA) among pregnant women who presented to Hôpital Universitaire de Mirebalais (HUM) for antenatal care and returned for facility delivery ( $\mathrm{n=972)}$

\begin{tabular}{|c|c|c|c|c|c|c|}
\hline \multirow[b]{2}{*}{ Variable } & \multicolumn{3}{|c|}{ Unadjusted } & \multicolumn{3}{|c|}{ Adjusted } \\
\hline & OR & $95 \% \mathrm{Cl}$ & $P$ value & AOR & $95 \% \mathrm{CI}$ & $P$ value \\
\hline \multicolumn{7}{|l|}{ Age (years) } \\
\hline$<20$ & 1.30 & 0.83 to 2.03 & 0.25 & 1.09 & 0.68 to 1.75 & 0.72 \\
\hline 20-34 & Ref & & & Ref & & \\
\hline$>34$ & 1.53 & 1.06 to 2.20 & 0.024 & 1.76 & 1.18 to 2.59 & 0.01 \\
\hline Distance from town to hospital (km) & 1.01 & 0.99 to 1.02 & 0.35 & & & \\
\hline Probability of poverty* & 1.01 & 0.94 to 1.08 & 0.83 & 1.01 & 0.96 to 1.07 & 0.86 \\
\hline Pesticide use in the past year & 1.06 & 0.69 to 1.64 & 0.78 & & & \\
\hline Twin pregnancy & 252 & 1.08 to 6.08 & 0.0395 & 3.28 & 1.20 to 8.95 & 0.019 \\
\hline First pregnancy & 1.40 & 1.09 to 1.79 & 0.0084 & 1.57 & 1.12 to 2.23 & 0.0085 \\
\hline No. of prior live births & 0.96 & 0.86 to 1.06 & 0.39 & & & \\
\hline No. of prior stillbirths & 1.25 & 0.88 to 1.77 & 0.20 & 1.38 & 0.97 to 1.95 & 0.077 \\
\hline No. of prior miscarriages & 0.80 & 0.53 to 1.22 & 0.30 & & & \\
\hline No. of prior abortions & 0.40 & 0.17 to 0.96 & 0.040 & 0.41 & 0.17 to 0.97 & 0.044 \\
\hline \multicolumn{7}{|l|}{ Food Consumption Score } \\
\hline Acceptable & Ref & & & & & \\
\hline Borderline & 1.21 & 0.76 to 1.91 & 0.42 & & & \\
\hline Poor & 1.25 & 0.56 to 2.77 & 0.59 & & & \\
\hline \multicolumn{7}{|l|}{ Household Hunger Scale } \\
\hline No hunger & Ref & & & & & \\
\hline Moderate & 1.08 & 0.76 to 1.54 & 0.65 & & & \\
\hline Severe & 0.87 & 0.62 to 1.24 & 0.45 & & & \\
\hline
\end{tabular}

${ }^{*}$ Per 0.1 increase in probability of poverty household consumption less than one dollar per day. HUM, Hôpital Universitaire de Mirebalais; km, kilometre; SGA, small for gestational age.

had an abortion, with women in the middle wealth quintile having a 3.3 times greater odds of reporting a prior abortion, and women in the top two wealth quintiles having a 7.4 times greater odds, compared with women in the bottom two wealth quintiles. ${ }^{34}$ Other studies have found a decreased risk of SGA for women from wealthier households. ${ }^{5}$ Women who have had abortions may also have longer interpregnancy periods, perhaps leaving them healthier or with increased resources during a subsequent pregnancy.

We identified a number of risk factors for preterm birth and SGA that have been reported in other settings, indicating some consistency between rural Haiti and other settings ranging from rural to urban and low to high income. The association between low and high maternal age and preterm birth has been well documented, ${ }^{4}$ although the underlying reason for this association is unknown. For older mothers, it may relate in part to a higher prevalence of other comorbidities that increase risk of preterm birth, like hypertension, diabetes and thyroid disease. ${ }^{4}$ High maternal age (potentially for similar reasons as with preterm birth), twin pregnancy (because of shared uterine environment) and first pregnancy (for both social and biological reasons) have all been found to confer increased risk for SGA in settings other than Haiti as well. ${ }^{5}$

This study is subject to some limitations. Our findings are among women who attended a facility for delivery and may not be generalisable to Haitian women who do not have a facility delivery. Women living in rural Haiti face impoverishment and limited public infrastructure and services, impacting their ability to consistently access healthcare. It is possible that women with high-risk pregnancies are more strongly encouraged to come to HUM for delivery, and thus overall rates of PTB and SGA may not reflect rates in the entire population. In a separate analysis, we found that participants who had a facility delivery had a lower probability of poverty and food insecurity compared with those who did not. ${ }^{14}$ As a result, there is risk of selection bias attenuating the identified relationship between food insecurity and preterm birth. We do not know the percent of eligible women who participated in the study or the reasons that eligible women who did not participate were not included; this may impact the generalisability of our findings. Because this study was originally intended to assess for arbovirus prevalence in pregnant 
women, we did not comprehensively collect maternal comorbidities and were unable to determine the specific contributions of these conditions to preterm birth and SGA. We also do not have information about maternal nutrition, which may be an important mediator between food insecurity and preterm birth. There may be additional unmeasured variables that confound the relationships between the risk factors identified in this study and preterm birth or SGA, including length of interpregnancy period, psychosocial stress, mental health, pregnancy-related factors like pre-eclampsia and others.

\section{CONCLUSIONS}

In conclusion, this observational study of 1089 pregnant women receiving antenatal care and delivering at a rural tertiary care centre is the first to characterise risk factors for preterm birth and SGA in rural Haiti. We found that maternal age less than 20 or greater than 34 years and severe household food insecurity were independently associated with greater risk of preterm birth; that age greater than 34 years, twin pregnancy and first pregnancy were independently associated with greater risk of an infant born SGA; and that number of prior abortions was independently associated with a reduced risk of an infant born SGA. The association between food insecurity and preterm birth highlights a potentially important intervention target to improve birth outcomes as obstetrical services are expanded in resource-limited settings.

Twitter Louise C Ivers @drlouiseivers

Contributors LIC, MFF, GJ, JPJ, CM and MR designed and implemented the study. AR performed the primary data analysis and wrote the first draft of the manuscript. $\mathrm{AH}$ performed the literature review. All authors provided critical feedback on the manuscript.

Funding The study was funded by the US Centers for Disease Control and Prevention/Unite de Gestion de Projets, Haiti (5U01GGH001060-04) and the Global Health Research Core of Harvard Medical School.

Competing interests None declared.

Patient and public involvement Patients and/or the public were not involved in the design, or conduct, or reporting, or dissemination plans of this research.

Patient consent for publication Not required.

Ethics approval Ethical approval was granted by the Institutional Review Boards of Partners HealthCare (Boston, Massachusetts; protocol number 2017P000366) and Haiti's National Bioethics Committee (Port-au-Prince, Haiti; protocol number 161728).

Provenance and peer review Not commissioned; externally peer reviewed.

Data availability statement Data are available on request. Deidentified data can be made available for legitimate research purposes if requested from the senior author (LCl).

Open access This is an open access article distributed in accordance with the Creative Commons Attribution Non Commercial (CC BY-NC 4.0) license, which permits others to distribute, remix, adapt, build upon this work non-commercially, and license their derivative works on different terms, provided the original work is properly cited, appropriate credit is given, any changes made indicated, and the use is non-commercial. See: http://creativecommons.org/licenses/by-nc/4.0/.

ORCID iD

Louise C Ivers http://orcid.org/0000-0003-2314-9230

\section{REFERENCES}

1 Matthews TJ, MacDorman MF, Thoma ME. Infant mortality statistics from the 2013 period linked Birth/Infant death data set. Nat/ Vital Stat Rep 2015;64:1-30.

2 Watkins WJ, Kotecha SJ, Kotecha S. All-Cause mortality of low birthweight infants in infancy, childhood, and adolescence: population study of England and Wales. PLOS Med 2016;13:e1002018.

3 Chawanpaiboon S, Vogel JP, Moller A-B, et al. Global, regional, and national estimates of levels of preterm birth in 2014: a systematic review and modelling analysis. Lancet Glob Health 2019;7:e37-46.

4 Goldenberg RL, Culhane JF, lams JD, et al. Epidemiology and causes of preterm birth. Lancet 2008;371:75-84.

5 McCowan L, Horgan RP. Risk factors for small for gestational age infants. Best Pract Res Clin Obstet Gynaecol 2009;23:779-93.

6 United Nations Development Programme. Goal 3: good health and well-being, 2019. Available: https://www.undp.org/content/undp/en/ home/sustainable-development-goals/goal-3-good-health-and-wellbeing.html [Accessed 17 Jun 2019].

7 Institut Haïtien de l'Enfance IHEH, Icf. Haiti Enquíte Mortalitè, Morbiditè et Utilisation des Services 2016-2017 - EMMUS-VI. Pètion-Ville/Haiti: IHE/Haiti, ICF 2018

8 Blencowe $\mathrm{H}$, Cousens S, Oestergaard MZ, et al. National, regional, and worldwide estimates of preterm birth rates in the year 2010 with time trends since 1990 for selected countries: a systematic analysis and implications. Lancet 2012;379:2162-72.

9 Rashid A, Park T, Macneal K, et al. Maternal diet and morbidity factors associated with low birth weight in Haiti: a case-control study. Health Equity 2018;2:139-44.

10 Cianelli R, Mitchell E, Albuja L, et al. Maternal - Child Health Needs Assessment in Haiti. Int J Appl Sci Technol 2014;4:30-8.

11 Schreiner M. A simple poverty score care for Haiti, 2016. Available: http://www.simplepovertyscorecard.com/HTI_2012_ENG.pdf [Accessed 28 Oct 2018].

12 Deitchler M, Ballard T, Swindale A, et al. Introducing a simple measure of household hunger for cross-cultural use. Washington, DC: Food and Nutrition Technical Assistance II project, AED, 2011.

13 World Food Programme Food consunmption analysis: calculation and use of the Food Consumption Score in food consumption and food security analysis. Technical guidance sheet. Rome: World Food Programme, 2008.

14 Raymondville M, Rodriguez C, Richterman A, et al. Barriers and facilitators influencing Facility-Based delivery in rural Haiti: a mixed methods study with a convergent design;2020.

15 Estimates of burden and consequences of infants born small for gestational age in low and middle income countries with INTERGROWTH-21st standard: analysis of CHERG datasets. BMJ 2017;358:j4229.

16 Food Insecurity and Public Health: CRC Press, Taylor \& Francis Group 2015.

17 Gundersen C, Tarasuk V, Cheng J, et al. Food insecurity status and mortality among adults in Ontario, Canada. PLoS One 2018;13:e0202642

18 Dolatian M, Sharifi N, Mahmoodi Z. Relationship of socioeconomic status, psychosocial factors, and food insecurity with preterm labor: a longitudinal study. Int J Reprod Biomed 2018;16:563-70.

19 Zar HJ, Pellowski JA, Cohen S, et al. Maternal health and birth outcomes in a South African birth cohort study. PLoS One 2019;14:e0222399-e99.

20 Tucker CM, Berrien K, Menard MK, et al. Predicting preterm birth among women screened by North Carolina's pregnancy medical home program. Matern Child Health J 2015;19:2438-52.

21 Siega-Riz AM, Herrmann TS, Savitz DA, et al. Frequency of eating during pregnancy and its effect on preterm delivery. Am J Epidemiol 2001;153:647-52.

22 Laraia BA, Siega-Riz AM, Gundersen C, et al. Psychosocial factors and socioeconomic indicators are associated with household food insecurity among pregnant women. J Nutr 2006;136:177-82.

23 Hromi-Fiedler A, Bermúdez-Millán A, Segura-Pérez S, et al. Household food insecurity is associated with depressive symptoms among low-income pregnant Latinas. Matern Child Nutr 2011;7:421-30.

24 Laraia BA, Leung CW, Murphy A. Health and developmental correlates of child food insecurity from pregnancy to early childhood national academies of science Steering Committee on research gaps and opportunities on the causes and consequences of child hunger 2013.

25 Glynn LM, Schetter CD, Hobel CJ, et al. Pattern of perceived stress and anxiety in pregnancy predicts preterm birth. Health Psychol 2008;27:43-51. 
26 Hobel CJ, Goldstein A, Barrett ES. Psychosocial stress and pregnancy outcome. Clin Obstet Gynecol 2008;51:333-48.

27 Gowda C, Hadley C, Aiello AE. The association between food insecurity and inflammation in the US adult population. Am J Public Health 2012;102:1579-86.

28 Ford ES. Food security and cardiovascular disease risk among adults in the United States: findings from the National health and nutrition examination survey, 2003-2008. Prev Chronic Dis 2013;10:E202.

29 Boyle AK, Rinaldi SF, Norman JE, et al. Preterm birth: inflammation, fetal injury and treatment strategies. J Reprod Immunol 2017;119:62-6.

30 The Economist intelligence unit. global food security index, 2017. Available: https://foodsecurityindex.eiu.com/Index [Accessed 22 June 2018].
31 World Food Programme. WFP Haiti country brief: October 2019. Available: https://docs.wfp.org/api/documents/WFP-0000110873/ download/?_ga=2.69195096.8378217.1575568331-1542983842. 1575568331 [Accessed 12 May 2019].

32 Soneji S, Beltrán-Sánchez H. Association of special supplemental nutrition program for women, infants, and children with preterm birth and infant mortality. JAMA Netw Open 2019;2:e191 6722-e22.

33 Pickering RM, Forbes JF. Risks of preterm delivery and small-forgestational age infants following abortion: a population study. $\mathrm{Br} \mathrm{J}$ Obstet Gynaecol 1985;92:1106-12.

34 Meffen K, Burkhardt G, Bartels S. Abortion care in Haiti: a secondary analysis of demographic and health data. PLoS One 2018;13:e0206967. 